\title{
FAKTOR PENENTU KEPUTUSAN PEMBELIAN BERAS DI KIOS REJO MAKMUR, SALATIGA
}

\author{
(Determining Factors For Purchase Of Rice In Kios Rejo Makmur, Salatiga)
}

\author{
Laila Kusumaning Ayu ${ }^{1}$ dan Lasmono Tri Sunaryanto ${ }^{2}$ \\ Program Studi Agribisnis, Fakultas Pertanian dan Bisnis Universitas Kristen Satya Wacana \\ Jl. Diponegoro 52-60 Salatiga 50711, Jawa Tengah-Indonesia \\ email: kusumaninglaila@gmail.com¹ lasmono@staff.uksw.edu²
}

Article Submitted : 12-05-2020

Article Accepted : 29-05-2020

\begin{abstract}
Indonesia is the highest consumer of rice per capita in the world with the largest amount. The main factor driving high consumption is the large population. The high consumption of rice also affects the competition for rice sales. Increasingly high competition makes rice producers begin to learn about rice purchasing decisions. This study aims to analyze the factors that influence rice purchasing decisions in Rejo Makmur Kiosk, Salatiga. This research uses descriptive qualitative method with multiple linear regression analysis. Respondents obtained by accidental sampling method and data obtained using a questionnaire. The results showed that price (X1), product (x2), promotion (X3), and location (X4) factors simultaneously had a significant effect on rice purchasing decisions (Y) in Rejo Makmur Kiosk. Partially the factors that have a significant influence on consumer purchasing decisions are price, product and promotion factors, while location factors have no effect. The ability of the independent variable in explaining the purchase decision variable is $75.4 \%$, while the remaining $24.6 \%$ is influenced by other variables outside this regression equation or unknown variables.
\end{abstract}

Keywords: Rice, Price, Product, Promotion, and Location

\section{PENDAHULUAN}

Indonesia merupakan salah satu konsumen beras per kapita terbesar di dunia. Total konsumsi beras Indonesia tercatat pada tahun 2018 sebesar 32,42 juta ton. Faktor utama yang mendorong tingginya konsumsi adalah jumlah penduduk yang semakin besar. Tingginya konsumsi beras di Indonesia juga dikarenakan adanya budaya makan rakyat Indonesia yang merasa belum makan jika belum mengkonsumsi nasi, meskipun kebutuhan karbohidratnya sudah dipenuhi dari makanan lain (Badan Pusat Statistik 2018).

Kebutuhan konsumen akan berbedabeda antara konsumen satu dengan yang lain. Perbedaan kebutuhan beras ini dipengaruhi oleh beberapa faktor antara lain pendapatan, selera konsumen, kualitas beras dan harga beras. Menurut Handoko dkk (2001), segmen konsumen beras berbeda antara konsumen dengan pendapatan atas, menengah dan bawah. Namun secara umum sekitar 60\% masyarakat masih memilih beras yang murah dengan kualitas yang rendah sampai sedang, sementara sisanya sekitar $40 \%$ memilih beras dengan kualitas yang bagus. Dengan banyaknya kebutuhan konsumen beras di Indonesia maka peluang untuk memasarkan produk beras sangatlah tinggi. 
Beras sebagai bahan pangan pokok bagi sebagian besar rakyat Indonesia mempunyai peluang yang besar bagi pengembangannya, khususnya dibidang pengembangan pasar atau perdagangannya. Peluang ini salah satunya dapat diwujudkan dengan membuat produk beras memiliki nilai tambah yang lebih baik dibandingkan dengan produk beras yang telah ada di pasaran, baik itu dari segi kualitas maupun dari segi kuantitas. Salah satu alternatif yang dapat dilakukan yaitu dengan meningkatkan kualitas beras dimulai dari pemilihan beras dengan kualitas terbaik sampai dengan proses akhir yaitu dengan pemberian kemasan yang menarik yang bertujuan tidak hanya menarik perhatian konsumen saja, namun lebih dari itu yaitu untuk meningkatkan mutu beras tersebut secara tidak langsung.

Produk beras dalam kemasan dapat dikatakan sebagai produk baru yang menyuguhkan inovasi yang memiliki keunggulan tersendiri. Produk beras dalam kemasan yang sekarang banyak dijumpai dipasaran yang merupakan diversifikasi produk yang telah ada sebelumnya, harus diupayakan pemahaman perilaku konsumen oleh produsen beras dalam kemasan dalam upayanya agar produk tersebut dapat laku dipasaran. Untuk itulah para pengelola atau pedagang produk ini harus mampu mengidentifikasi perilaku konsumen, terutama mengenai kebutuhan konsumen terhadap produk beras.

Keputusan pembelian merupakan suatu keputusan sebagai pemilihan suatu tindakan dari dua atau lebih pilihan alternatif (Sumarwan, 2011). Pada pengambilan keputusan pembelian, terdapat banyak faktor yang dapat mempengaruhi konsumen dalam mengambil keputusan pembelian, contohnya adalah produk, harga, promosi, lokasi, kualitas layanan, merek, distribusi, citra rasa dll.

\section{METODE PENELITIAN}

Penelitian dilaksanakan dari bulan Januari s/d April 2019 di Kios Rejo Makmur yang terletak di Pasar Blauran Jalan Taman Pahlawan, Salatiga, Jawa Tengah. Alasan memilih tempat ini karena kios ini memiliki beragam merk beras dan juga penjualan ditempat ini sangat laris dibandingkan dengan kios lainya yang berada di Pasar Blauran. Penelitian ini menggunakan pendekatan deskriptif kuantitatif dengan metode survei yang menggunakan kuesioner sebagai alat penelitian dan deskriptif kualitatif dengan skala likert. Metode Penelitian Kuantitatif, sebagaimana dikemukakan oleh Sugiyono, 2012. yaitu: Metode penelitian yang digunakan untuk meneliti pada populasi atau sampel tertentu, pengumpulan data menggunakan instrumen penelitian, analisis data bersifat kuantitatif/statistik, dengan tujuan untuk menguji hipotesis yang telah ditetapkan. Tujuan penelitian ini menganalisis faktorfaktor yang mempengaruhi keputusan pembelian Beras di Kios Rejo Makmur.

Pengambilan sampel dalam penelitian ini menggunakan metode non probability sampling. Non probability sampling adalah teknik pengambilan sampel yang tidak memberikan peluang atau kesempatan yang sama bagi setiap unsur atau anggota populasi untuk dipilih menjadi sampel (Sugiyono, 2008). Sampel yang dipilih menggunakan teknik accidental sampling. Sampling accidental adalah teknik penentuan sampel berdasarkan kebetulan, yaitu siapa saja yang sudah melakukan pembelian dan bersedia di wawancarai. Dalam penelitian ini kriteria yang digunakan dalam pemilihan sampel adalah orang yang membeli beras di Pasar Blauran Kota Salatiga. Tingkat kesalahan yang saya gunakan pada penelitian ini 0,05 atau 5\% dan jumlah responden yang baik disarankan untuk keakuratan data antara 30 sampai 500 responden. Maka jumlah responden yang saya ambil berjumlah 50 responden. Teknik pengumpulan data yang akan dilakukan 
dengan pengumpulan dari data primer dan data sekunder dimana data primer yang meliputi dengan cara wawancara, pemberian kuesioner serta dokumentasi atau pertanyaan kepada responden sedangkan data sekunder diperoleh dari instasi atau lembaga yang terkait dengan penelitian, literatur, pada buku atau internet. Analisis ini untuk mengetahui besarnya pengaruh variabel bauran pemasaran (produk, harga, promosi, dan distribusi) terhadap keputusan pembelian ulang.

Rumus :

$\mathrm{Y}=\alpha+\beta 1 X 1+\beta 2 X 2+\beta 3 X 3+\beta 4 X 4+e$

Keterangan:

$\mathrm{Y}$ : Keputusan untuk membeli

$\alpha$ : konstanta

$\mathrm{X} 1$ : produk

$\mathrm{X} 2$ : harga

$\mathrm{X} 3$ : promosi

$\mathrm{X} 4$ : lokasi

Uji $F$ ini digunakan untuk mengetahui apakah variabel independen (X1, X2, .. Xn) secara simultan berpengaruh secara signifikan terhadap variabel dependen (Y) atau untuk mengetahui apakah model regresi dapat digunakan untuk memprediksikan variabel dependen atau tidak.

a. Fhitung > Ftabel, maka H0 ditolak dan Ha diterima artinya variasi dari model regresi berhasil menerangkan bahwa ada pengaruh yang signifikan dari variabel independen (X1, X2, X3, X4) secara simultan terhadap variabel dependen $(\mathrm{Y})$.

b. Fhitung < Ftabel, maka H0 diterima dan Ha ditolak artinya variasi dari model regresi ini menerangkan bahwa tidak ada pengaruh yang signifikan dari variabel independen $(\mathrm{X} 1, \mathrm{X} 2, \mathrm{X} 3, \mathrm{X} 4)$ secara simultan terhadap variabel $(\mathrm{Y})$.

Uji $\mathrm{T}$ digunakan untuk mengetahui pengujian tingkat signifikan secara parsial antara variabel bebas terhadap variabel terikat dengan menggunakan uji $\mathrm{t}$ dengan langkah-langkah sebagai berikut:

a. Jika thitung $\leq \mathrm{t}$ tabel atau probabilitas (nilai Sig) $\geq 0,05$ maka $\mathrm{H} 0$ diterima dan $\mathrm{Ha}$ ditolak.

b. Jika thitung $>\mathrm{t}$ tabel atau probabilitas (nilai Sig) $<0,05$ maka H0 ditolak dan $\mathrm{Ha}$ diterima.

\section{HASIL DAN PEMBAHASAN}

\section{Karakteristik Responden}

Adapun karaktristik responden meliputi: jenis kelamin, tingkat pendidikan, dan umur. Karakteristik merupakan hasil yang diperoleh dari data primer dari hasil survei responden dengan mengunakan panduan kuesioner.

Tabel 1. Karakteristik Responden

\begin{tabular}{lcc}
\hline Karakteristik & Frekuensi & Presentase (\%) \\
\hline A.Jenis Kelamin & & 66 \\
Laki-laki & 17 & 34 \\
Perempuan & 33 & 100 \\
\hline Total & 50 & \\
\hline B.Tingkat Pendidikan & & 16 \\
SD & 8 & 24 \\
SMP & 12 & 44 \\
SMA & 22 & 16 \\
S1 & 8 & 100 \\
\hline Total & 50 & \\
\hline
\end{tabular}




\begin{tabular}{lcc}
\hline C.Umur (tahun) & \\
$21-29$ & 3 & 6 \\
$30-39$ & 12 & 24 \\
$40-49$ & 12 & 24 \\
$50-59$ & 20 & 40 \\
$60-63$ & 3 & 6 \\
\hline Total & 50 & 100 \\
\hline
\end{tabular}

Sumber: Data primer yang diolah (2020).

Berdasarkan tabel 1 dapat dilihat bahwa responden yang paling banyak adalah jenis kelamin Perempuan sebanyak 33 orang dengan presentase sebesar $66 \%$. Adapun pengambilan sampel dalam penelitian ini tidak ditentukan jumlah perempuan harus lebih unggul dari laki - laki melainkan berdasarkan hasil penelitian yang terdapat dilapangan terbukti pengunjung perempuan lebih sering berkunjung di Kios Rejo Makmur Salatiga. Berdasarkan hasil analisis pada tabel 1 paling banyak responden yang membeli beras Kios Rejo Makmur adalah responden yang mengambil SMA dengan presentase $44 \%$. Pada penelitian ini tidak ada batas umur yang ditetapkan untuk

\section{Koefisien Determinasi (R2)}

Tabel 2. Hasil Koefisien Determinasi

\begin{tabular}{|c|c|c|c|c|c|c|c|c|}
\hline \multirow{2}{*}{ Model } & \multirow{2}{*}{$\mathrm{R}$} & \multirow{2}{*}{ R Square } & \multirow{2}{*}{$\begin{array}{c}\text { Adjusted R } \\
\text { Square }\end{array}$} & \multirow{2}{*}{$\begin{array}{l}\text { Std. Error } \\
\text { of the } \\
\text { Estimate }\end{array}$} & \multicolumn{4}{|c|}{ Change Statistics } \\
\hline & & & & & $\begin{array}{l}\text { R Square } \\
\text { Change }\end{array}$ & df1 & df 2 & $\begin{array}{c}\text { Sig. F } \\
\text { Change }\end{array}$ \\
\hline 1 & $869(a)$ & ,754 & 722 & 781 & ,754 & 4 & 45 &, 000 \\
\hline
\end{tabular}

a Predictors: (Constant), lokasi (X4), promosi (X3), produk (X2), harga (X1)

b Dependent Variable: Keputusan Pembelian (Y)

Sumber: Output SPSS, 2020

Berdasarkan tabel 2 dapat disimpulkan bahwa nilai koefisien determinasi (R2) sebesar 0,754 atau 75,4\%. Besarnya nilai koefisien determinasi tersebut menunjukkan bahwa kemampuan variabel

\section{Persamaan Regresi}

Persamaan regresi linier berganda dalam penelitian ini adalah sebagai berikut: menjadi responden melainkan semua umur bisa menjadi responden asalkan konsumen tersebut melakukan pembelian di Kios Rejo Makmur. Dapat dilihat pada tabel 1 diatas umur yang paling banyak melakukan pembelian beras Kios Rejo Makmur ialah responden pada umur 50-59 tahun dengan presentase $40 \%$.

Penelitian ini bertujuan untuk mengetahui pengaruh variabel-variabel yang terdiri dari Harga (X1), Produk (X2), Promosi (X3), dan Lokasi (X4) terhadap Keputusan Pembelian Beras di Kios Rejo Makmur, dengan menggunakan alat analisis sebagai berikut:

Nilai koefisien determinasi dapat dilihat pada tabel 2 berikut: 
Y : Variabel Keputusan Pembelian

X1 : Variabel Harga

X2 : Variabel Produk

X3 : Variabel Promosi

X4 : Variabel Lokasi

Adapun interpretasi dari model persamaan regresi di atas adalah sebagai berikut:

Nilai Konstanta sebesar 2,583 artinya jika tidak terjadi perubahan variabel harga, produk, promosi dan lokasi maka keputusan pembelian di Kios Rejo Makmur bernilai positif dan menunjukkan besarnya pengaruh keputusan pembelian (Y) sebesar 2,583 satuan. Hal ini sama dengan penelitian yang dilakukan Pertiwi,dkk (2016) hasil konstanta diperoleh sebesar 7,772 adalah bernilai positif yang menunjukkan besarnya pengaruh Keputusan Pembelian (Y). Apabila variabel bebas Produk (X1), Harga (X2), Promosi (X3), dan Tempat (X4) dianggap tidak ada atau $=0$

Dari hasil koefisien regresi X1 sebesar 52,6 persen, maka untuk setiap kenaikan harga sebesar 1 persen akan meningkatkan keputusan pembelian beras Kios Rejo Makmur sebesar 52,6 persen. Begitu juga sebaliknya, apabila harga mengalami penurunan sebesar 1 persen maka keputusan pembelian akan mengalami penurunan sebesar 52,6 persen. Hal ini sama dengan penelitian yang dilakukan Pertiwi,dkk (2016) Nilai koefisien regresi variabel harga (b2) bernilai positif yaitu 0,085 . Artinya apabila ada peningkatan kinerja Harga (X2), maka keputusan pembelian donut Baker's King juga akan mengalami peningkatan sebesar 0,085.

Dari hasil koefisien regresi X2 sebesar 44,2 persen, maka untuk setiap kenaikan produk sebesar 1 persen, maka akan meningkatkan keputusan pembelian beras Kios Rejo Makmur sebesar 44,2 persen. Begitu juga sebaliknya, apabila produk mengalami penurunan 1 persen maka keputusan pembelian akan mengalami penurunan sebesar 44,2 persen. Hal ini sama dengan penelitian yang dilakukan
Pertiwi,dkk (2016) yang berjudul Pengaruh Bauran Pemasaran Terhadap Keputusan Pembelian Baker's King Donuts and Coffee Nilai koefisien regresi variabel produk (b1) bernilai positif yaitu 0,337 . Artinya apabila ada peningkatan kinerja Produk (X1), maka keputusan pembelian donut Baker's King juga akan mengalami peningkatan sebesar 0,337 .

Dari hasil koefisien regresi X3 sebesar 25,6 persen, maka untuk setiap kenaikan promosi sebesar 1 persen, maka akan meningkatkan keputusan pembelian beras Kios Rejo Makmur sebesar 25,6 persen. Begitu juga sebaliknya, apabila promosi mengalami penurunan 1 persen maka keputusan pembelian akan mengalami penurunan sebesar 25,6 persen. Hal ini sama dengan penelitian yang dilakukan Pertiwi,dkk (2016) yang berjudul Pengaruh Bauran Pemasaran Terhadap Keputusan Pembelian Baker's King Donuts and Coffee Nilai koefisien regresi variabel promosi (b3) bernilai positif yaitu 0,379 . Artinya apabila ada peningkatan kinerja Promosi (X3), maka keputusan pembelian donut Baker's King juga akan mengalami peningkatan sebesar 0,379 .

Dari hasil koefisien regresi X4 sebesar $-16,9$ persen dikarenakan hasil lokasi negatif maka dapat disimpulkan bahwa, setiap kenaikan maupun penurunan lokasi sebesar 1 persen maka keputusan pembelian beras Kios Rejo Makmur sebesar -16,9 persen. Dikarenakan lokasi Kios Rejo Makmur memang strategis tetapi lahan parkir sedikit susah dan tempat sempit, sehingga mengurangi keputusan pembelian. Hal ini berbeda dengan penelitian yang dilakukan Pertiwi,dkk (2016) yang berjudul Pengaruh Bauran Pemasaran Terhadap Keputusan Pembelian Baker's King Donuts and Coffee karena hasil penelitian tersebut mempunyai nilai koefisien regresi variabel produk (b4) bernilai positif yaitu 0,251 . Artinya apabila ada peningkatan kinerja Tempat (X4), maka keputusan pembelian donut Baker's King 
juga akan mengalami peningkatan sebesar

0,251

\section{Uji Signifikansi Parsial (uji t)}

Tabel 3. Perbandingan antara t-hitung dan t-tabel, serta nilai Sig-t dan Sig- $\alpha$ dari masing-masing variabel bebas

\begin{tabular}{llccccl}
\hline No & Variabel Bebas & $\begin{array}{c}\mathrm{t} \\
\text { hitung }\end{array}$ & $\begin{array}{c}\mathrm{t} \\
\text { tabel }\end{array}$ & Sig-t & Sig- $\alpha$ & Kesimpulan \\
\hline 1. & Harga (X1) & $3,824>$ & 2,014 & $0,00<$ & 0,05 & Signifikan \\
2. & Produk (X2) & $2,384>$ & 2,014 & $0,02<$ & 0,05 & Signifikan \\
3. & Promosi (X3) & $2,726>$ & 2,014 & $0,00<$ & 0,05 & Signifikan \\
4. & Lokasi (X4) & $-0,446<$ & 2,014 & $0,65>$ & 0,05 & Tidak Signifikan \\
\hline
\end{tabular}

Sumber: Data diolah Penulis, (2020)

Hasil uji t untuk harga (X1) terhadap keputusan pembelian (Y) menunjukkan nilai Sig 0,00 dan $t$ hitung menunjukkan nilai 3,824 artinya nilai Sig lebih kecil dari nilai probabilitas $0,05(0,00<0,05)$ dan $t$ hitung lebih besar dari t tabel $(3,824>2,014)$, maka kesimpulan yang dapat diambil adalah $\mathrm{H} 0$ ditolak dan $\mathrm{Ha}$ diterima. Ini berarti harga berpengaruh signifikan secara parsial terhadap keputusan pembelian beras Kios Rejo Makmur. Hasil tersebut mendukung penelitian yang pernah dilakukan sebelumnya oleh Hamdani (2015) yang mengemukakan bahwa harga secara signifikan mempengaruhi minat konsumen untuk membeli, semakin baik harga yang ditawarkan sesuai dengan kualitasnya maka mempengaruhi keputusan pembelian beras terhadap konsumen.

Hasil uji t untuk produk (X2) terhadap keputusan pembelian $(\mathrm{Y})$ menunjukkan nilai Sig 0,02 dan $t$ hitung menunjukkan nilai 2,384 artinya nilai Sig lebih kecil dari nilai probabilitas $0,05(0,02<0,05)$ dan $\mathrm{t}$ hitung lebih besar dari t tabel $(2,384>2,014)$, maka kesimpulan yang dapat diambil adalah $\mathrm{HO}$ ditolak dan Ha diterima. Ini berarti produk berpengaruh signifikan secara parsial terhadap keputusan pembelian beras Kios Rejo Makmur. Hasil tersebut mendukung penelitian yang pernah dilakukan sebelumnya oleh Munandar (2014) yang mengemukakan bahwa ketika produk sudah melekat dihati konsumen sikap konsumen yang menyukai produk beras lokal menunjukkan perilaku yang loyal terhadap produk tersebut.

Hasil uji t untuk promosi (X3) terhadap keputusan pembelian (Y) menunjukkan nilai Sig 0,00 dan t hitung menunjukkan nilai 2,726 artinya nilai Sig lebih kecil dari nilai probabilitas $0,05(0,00$ $<0,05)$ dan $t$ hitung lebih besar dari t tabel $(2,726>2,014)$, maka kesimpulan yang dapat diambil adalah $\mathrm{H} 0$ ditolak dan $\mathrm{Ha}$ diterima. Ini berarti promosi berpengaruh signifikan secara parsial terhadap keputusan pembelian beras Kios Rejo Makmur. Hasil tersebut berbeda dengan penelitian yang pernah dilakukan sebelumnya oleh Hamdani (2015) yang mengemukakan bahwa promosi berpengaruh tidak signifikan terhadap minat konsumen untuk membeli. Artinya, ada atau tidaknya promosi, tidak berpengaruh signifikan terhadap keputusan pembelian beras lokal di Pasar Tradisional padahal semakin banyak promosi semakin banyak juga masyarakat yang mengetahui produk tersebut dan dapat meningkatkan penjualan produk.

Hasil uji t untuk lokasi (X4) terhadap keputusan pembelian (Y) menunjukkan nilai Sig 0,65 dan t hitung menunjukkan nilai 0,446 artinya nilai Sig lebih besar dari nilai probabilitas $0,05(0,65>0,05)$ dan $t$ hitung lebih kecil dari $\mathrm{t}$ tabel $(-0,446<2,014)$, 
maka kesimpulan yang dapat diambil adalah HO diterima dan Ha ditolak. Ini berarti lokasi tidak berpengaruh signifikan secara parsial terhadap keputusan pembelian beras Kios Rejo Makmur. Hasil tersebut berbeda dengan penelitian yang pernah dilakukan sebelumnya oleh Munandar (2014) yang mengemukakan bahwa distribusi secara signifikan mempengaruhi minat konsumen untuk membeli. Lokasi yang strategis akan memudahkan pelanggan untuk mendapatkan produk beras lokal tersebut. Lokasi Kios Rejo Makmur strategis tetapi kurang nyaman dan lahan parkir sempit jadi mengurangi minat beli konsumen.

Berdasarkan hasil pengujian yang dapat di lihat pada tabel 3 bahwa variabel yang paling berpengaruh terhadap keputusan

\section{Uji Signifikansi Simultan (Uji F)\}

pembelian adalah variabel harga, karena memiliki nilai beta lebih besar diantara variabel yang lain yaitu sebesar 0,471 dan memiliki nilai sig terkecil 0,000 . Hal ini berarti harga memiliki pengaruh yang besar terhadap keputusan pembelian

Secara parsial, yaitu harga (X1), produk (X2) dan promosi (X3) berpengaruh signifikan terhadap variabel keputusan pembelian beras Kios Rejo Makmur (Y) di Pasar Tradisional Baluran Kota Salatiga sedangkan variabel lokasi (X4) tidak berpengaruh signifikan terhadap variabel keputusan pembelian beras Kios Rejo Makmur (Y) di Pasar Tradisional Baluran Kota Salatiga

Hasil uji signifikansi simultan (Uji F) dapat dilihat pada tabel 4 berikut:

Tabel 4. Hasil Uji F

\begin{tabular}{lccccc}
\hline \multicolumn{1}{c}{ Model } & $\begin{array}{c}\text { Sum of } \\
\text { Squares }\end{array}$ & df & Mean Square & F & Sig \\
\hline 1 & 111,137 & 4 & & & \\
Regression & 148,783 & 45 & 27,784 & 8,403 &, $000^{\mathrm{a}}$ \\
$\quad$ Residual & 259,920 & 49 & 3,306 & & \\
$\quad$ Total & & & & \\
$\quad$
\end{tabular}

a. Predictors: (Constant), Lokasi (X4), Promosi (X3). Harga (X1), Produk (X2)

b. Dependent Variable: Keputusan Pembelian (Y)

Sumber: Output SPSS, (2020)

Berdasarkan tabel 4 nilai probabilitas (Sig) sebesar 0,000. Karena nilai Sig < 0,05 $(0,000<0,05)$, maka keputusannya adalah harga, produk, promosi dan lokasi signifikan terhadap keputusan pembelian beras Kios Rejo Makmur.

Dalam penelitian ini nilai $\mathrm{k}=5$ dan $\mathrm{n}$ $=50$. Maka nilai df 1 dalam penelitian ini adalah df $1=5-1=4$ dan df $2=50-5=45$, sehingga dengan melihat nilai pada $\mathrm{F}$ tabel dengan df $1=5$ dan df $2=45$ di peroleh nilai F tabel sebesar 2,58. Selanjutnya dapat dibandingan bahwa nilai $\mathrm{F}$ hitung dengan $\mathrm{F}$ tabel dari data di atas diketahui nilai $\mathrm{F}$ hitung sebesar 8,403 maka H0 di tolak dan Ha di terima. Sehingga dapat disimpulkan bahwa $\mathrm{F}$ hitung > F tabel $(8,403>2,58)$, artinya harga, produk, promosi dan lokasi berpengaruh signifikan secara simultan atau bersama-sama terhadap keputusan pembelian beras Kios Rejo Makmur.

Hal ini sesuai dengan penelitian yang dilakukan Ikasari,dkk (2016) yang menyatakan bahwa faktor produk (X1), harga (X2), tempat (X3), pribadi (X4), dan motivasi (X5) bersama-sama berpengaruh signifikan terhadap keputusan pembelian beras organik. 


\section{KESIMPULAN DAN SARAN}

\section{Kesimpulan}

1. Variabel bauran pemasaran yang terdiri dari Harga (X1), Produk (X2), Promosi (X3), dan Lokasi (X4) secara bersamasama atau simultan signifikan terhadap Keputusan Pembelian (Y).

2. Terdapat tiga variabel bebas yaitu Harga (X1), Produk (X2), dan Promosi (X3) yang secara parsial mempunyai pengaruh yang signifikan terhadap Keputusan Pembelian (Y), sedangkan Lokasi (X4) tidak mempunyai pengaruh signifikan terhadap Keputusan Pembelian (Y).

\section{Saran}

Dari hasil penelitian, analisis dan kesimpulan diatas, berikut beberapa saran

\section{DAFTAR PUSTAKA}

Alfajiri, Aldy. 2018. Hubungan Strategi Promosi Dengan Keputusan Pembelian Gadged Di Toko Suryaphone Samarinda. Jurnal. Fakultas Ilmu Sosial dan Ilmu Politik, Universitas Mulawarman, Vol 6, No 3, 2018.

Anggraini, Lulu Dian; Panji Deoranto; Dhita Morita Ikasari. 2016. Analisis Persepsi Konsumen Menggunakan Metode Importance Performance Analysis dan Customer Satisfaction Index dalam Jurnal Industri, Vol.4, No.2.

BPS Nasional. 2018. Data Konsumsi Beras per kapita di Indonesia.

Durianto, Darmadi, Sugiarto, Anton Wachidin Widjaya, Hendrawan Supratikno, 2003. Invasi Pasar dengan Iklan yang Efektif. Cetakan Pertama. PT. Gramedia Pustaka Utama, Jakarta.

Ghozali, I. 2006. Analisis Multivariate Lanjutan dengan SPSS Edisi 1. BP UNDIP, Semarang yang disampaikan kepada pihak Kios Rejo Makmur yaitu :

1. Berdasarkan hasil penelitian dapat diketahui harga merupakan variabel utama yang diperhatikan konsumen beras di Kios Rejo Makmur, karena itu produsen beras harus mempertahankan dan menyesuaikan harga beras sesuai dengan kualitas produk beras.

2. Penelitian selanjutnya disarankan dapat mengembangkan penelitian ini dengan menggunakan variabel-variabel yang berbeda agar bisa mengetahui seberapa besar suatu variabel terikat dapat dijelaskan oleh variabel-variabel bebas. Pemilihan

Hamdani. 2015. Analisis Pengaruh Bauran Pemasaran Terhadap Keputusan Untuk Membeli Ayam Goreng Rumah Makan "Tweety Fried Chicken" Di Kecamatan Tanah Grogot Kabupaten Paser. Skripsi. Sekolah Tinggi Ilmu Pertanian. Tanah Grogot.

Handoko, T. Hani. 2001. Manajemen Personalia dan Sumber Daya Manusia. Yogyakarta: BPFE Yogyakarta

Munandar. 2014. Pengaruh Bauran Pemasaran Dan Citra Merek Terhadap Keputusan Pembelian Yang Berdampak Pada Kepuasan Konsumen. Universitas PGRI. Yogyakarta.

Pertiwi, Marina Intan., dkk. (2016). "Pengaruh Bauran Terhadap Pemasaran Terhadap Keputusan Pembelian (Survei pada Konsumen Baker's King Donuts \& Coffee di MX Mall Malang)". Jurnal Administrasi Bisnis (JAB). Vol. 37. No. 1. Agustus. 2016. 179-186. 
Sant'Anna, A, P. 2014. Probabilistic priority numbers for failure modes and effects analysis. International Journal of Quality \& Reliability Management. 29(3):349-362

Suersh, K, Thomas, S, V, Suresh, G. 2011. Design, data analysis and sampling techniques for clinical research. Ann. Indian. Acad. Neurol. 14(4):287-290
Sugiyono, (2008). Metode Penelitian Kunatitatif Kualitatif dan R\&D. Bandung Alfabeta.

Sugiyono. 2012. Metode Penelitian Kuantitatif Kualitatif dan R\&D. Bandung: Alfabeta

Sumarwan, Ujang, Perilaku Konsumen : Teori dan Penerapannya Dalam Pemasaran, Penerbit Ghalia Indonesia, Bogor, 2011 